\title{
EDUCAÇÃO AMBIENTAL E A CONSTRUÇÃO DE PERCURSOS DIDÁTICOS DIALÓGICOS NO ENSINO MÉDIO
}

Suellen Maria Silva Dias ${ }^{1}$

Emanuel Souto da Mora Silveira²

Resumo: $O$ objetivo do trabalho é desenvolver um espaço de diálogo e reflexão sobre problemas ambientais contemporâneos, com foco na busca de alternativas e mudança de comportamento individual e coletivo. Uma proposta definida no âmbito do Ensino Médio, envolvendo estudantes da rede estadual de ensino em sequências didáticas centralizadas na atuação discente. $O$ desenvolvimento dos percursos didáticos revela que é possível mobilizar e sensibilizar os estudantes por meio de atividades que demandam baixo custo e estruturadas a partir de recursos disponíveis na maioria dos espaços escolares. As estratégias adotadas impactaram de forma direta no engajamento dos estudantes e mobilizaram discussões fundamentais para 0 momento que vivemos.

Palavras-chave: Capacidade Interventora; Sensibilização; Sequência Didática.

Abstract: The aim of the project is to develop a space for dialogue and reflection on contemporary environmental problems, with a focus on seeking alternatives and changing individual and collective behavior. A proposal defined in the sphere of High school, involving students from the public educational system in didactic sequences centralized in the student performance. The development of didactic course reveals that it is possible to mobilize and sensitize students through activities that demand low cost and structured from the resources available in most school spaces. The strategies adopted had a direct impact on student engagement and mobilized fundamental discussions for the moment we live.

Keywords: Capacity for Intervention; Awareness; Didactic Sequence.

${ }^{1}$ Rede Estadual de Ensino de Pernambuco. E-mail: suellen_silvadias@hotmail.com, Link para o Lattes: http://lattes.cnpq.br/8619883396019614

2 Universidade Federal de Pernambuco. E-mail: emanuel.silveira@ufpe.br,

Link para Lattes: http://lattes.cnpq.br/0732066954235310 


\section{Introdução}

Observa-se atualmente que a natureza é somente vista como provedora de recursos e receptora de resíduos. Eis, então, o princípio da degradação sem precedentes imposta à natureza, que se intensifica proporcionalmente ao processo de disseminação da cultura ocidental, que se transformou em ocidentalização, mundialização - globalização, sobretudo para saciar seu vício capitalista (RAMBO; RENK, 2008: p.75).

Dentre as temáticas mais discutidas na escola atual, a Educação Ambiental (EA) se destaca por sua importância no ensino de todas as disciplinas e por suas implicações na formação de estudantes conscientes (PEREIRA; GIBBON, 2014: p. 377). A Educação Ambiental sustenta uma recente discussão sobre as questões ambientais e transformações de conhecimentos, valores e atitudes que devem ser seguidos diante da nova realidade a ser construída, constituindo uma importante dimensão que necessita ser incluída no processo educacional (KONDRAT; MACIEL, 2013: p.826).

Nas escolas, a Educação Ambiental pode contribuir para a formação de cidadãos conscientes, aptos para decidirem e atuarem na realidade socioambiental. Para isso, é importante que mais do que informações e conceitos, a escola se disponha a trabalhar com atitudes, formação de valores e com mais ações práticas do que teóricas, para que o aluno possa aprender a amar, respeitar e praticar ações voltadas à conservação ambiental (MEDEIROS et al., 2011: p. 2).

A escolha do tema baseia-se na necessidade de desenvolver atividades voltadas para a Educação Ambiental em que não se entregue para o estudante meramente conceitos e informações. Sabe-se que é preciso criar estratégias de ensino que promovam engajamento e mobilização, bem como estimulem a reflexão e a capacidade crítica na busca por solução ou mitigação dos problemas ambientais.

Aliado a isso, compreende-se também a importância de oferecer recursos para que o engajamento dos estudantes propicie, em estágios mais avançados, formação de valores, mudanças de paradigmas e transformações atitudinais. É nesse sentido que está o ponto convergente da Educação Ambiental: promover transformações. Isso só é possível em circunstâncias em que o estudante se sinta motivado, envolvido, engajado e ciente do seu potencial transformador, tanto em nível local quanto global.

Diante do exposto, este trabalho tem o objetivo principal de desenvolver um espaço de reflexão e diálogo sobre problemas ambientais contemporâneos com foco na busca de alternativas e mudança de comportamento individual e coletivo, no contexto de uma sequência didática estruturada a partir de recursos audiovisuais. Para isso, será desenvolvida uma sequência didática com estudantes do Ensino Médio de uma escola da rede estadual de ensino. 


\section{Referencial Teórico}

Ao dizer que "nossa separação da natureza e de nossa natureza caracteriza uma mutilação do nosso ser, nos exilando de nossa matriz", Santos (2004, p. 449) reflete sobre o contexto atual da nossa sociedade. Entretanto, essa separação e consequências não são características gerais de todos os povos, sociedades e civilizações que já tenham existido. Tampouco é verdade que são características exclusivas da civilização contemporânea. É verdade, sim, o fato de que na civilização moderna a cisão entre os seres humanos e a natureza se tornou mais intensa, percebendo-se consideravelmente também suas consequências (RAMBO; RENK, 2008, p.62).

Nos últimos séculos, um modelo de civilização alicerçado no modelo industrial se impôs, proporcionando o desenvolvimento de novas tecnologias que tornaram os seres humanos capazes de exercer cada vez mais influência sobre o meio ambiente, acarretando ao Planeta uma acelerada degradação, que compromete a qualidade e a sobrevivência humana na biosfera e seu desequilíbrio. À medida que tal modelo de desenvolvimento econômico passou a provocar efeitos negativos mais graves, surgiram manifestações e movimentos que enfrentaram a crise ecológica e que refletiam a consciência de parcelas da população (DIDONET et al., 2015, p.3).

A partir desse processo de coisificação da natureza, também emerge a crise ambiental, ressaltada por Leff (2001, p.195) como resultante do desconhecimento da lei da entropia, o que tem desencadeado uma produção material sem limites e os limites dessa produção. E as possíveis soluções não podem ser baseadas nos princípios que "têm fundado o desastre ecológico, a alienação dos seres humanos e o descobrimento do mundo" (VIEGAS et al., 2016, p.90).

Diante da complexidade crescente dos problemas que afetam o meio ambiente, faz-se necessária uma abordagem mais ampla sobre o lugar em que se vive, pois somente assim será possível construir um mundo de pessoas conscientes às questões ambientais. Complexidade tornou-se uma palavrachave para descrever os desafios que envolvem a Educação Ambiental (ALMEIDA, 2019: p. 483).

Refletir sobre a complexidade ambiental abre uma estimulante oportunidade para compreender a gestação de novos atores sociais que se mobilizam para a apropriação da natureza, para um processo educativo articulado e compromissado com a sustentabilidade e a participação, apoiado numa lógica que privilegia o diálogo e a interdependência de diferentes áreas do saber. Mas também questiona valores e premissas que norteiam as práticas sociais prevalecentes, implicando mudança na forma de pensar e transformação no conhecimento e nas práticas educativas (JACOBI, 2003: p.191).

Nesse contexto, a Educação Ambiental crítica é uma ferramenta para enfrentar os conflitos e tensões entre sociedade e natureza, dada a importância 
dessa relação na formação do sujeito. Entendendo que o pensamento crítico, de acordo com Trein (2007, p.316), possui um papel relevante na formação de sujeitos capazes de criticar o atual modelo de sociedade e que buscam construir um projeto societário em que as relações de exploração sejam avaliadas profundamente.

A educação, em todas as suas formas, pode moldar o futuro de uma geração, modificando as atitudes das pessoas e repensando as práticas sociais, com base numa compreensão adequada e essencial do meio ambiente global e local, para construir uma sociedade planetária mais justa e ambientalmente sustentável. É um instrumento privilegiado para alcançar o desenvolvimento sustentável (DIDONET, 2015, p.6).

Compreender a crise socioambiental de forma crítica exige do educador a problematização e o conhecimento que considere a diversidade de concepções de sustentabilidade, seus valores, posições éticas, políticas e as implicações sociais (MALMANN, 2020, p.51).

Por isso, é tão importante que a Educação Ambiental seja abordada nos espaços escolares, porque esse ambiente pode ser capaz de modificar conceitos e atitudes, levando os estudantes a valorizar as questões ambientais (OLIVEIRA et al., 2015, p.323). Nessa direção ${ }_{2}$ Vido (2016, p.46) afirma que trabalhar valores humanos na escola é um desafio, pois os estudantes possuem outros valores - que não necessariamente são negativos do ponto de vista socioambiental. Porém, de um modo geral, o respeito pelo outro e a preocupação com a natureza estão dispersos, e nós, como educadores, devemos desenvolver ambos os valores em sala de aula, para formar cidadãos mais sensíveis à sociedade e à natureza.

Dentre os desafios encontrados, destacam-se àqueles em relação à fragmentação do conhecimento em áreas. Nas escolas isso se consolida nas variadas disciplinas, com lacunas nos diferentes níveis e modalidades de ensino. A elaboração dos materiais didáticos, de caráter informativo, que ignoram questões sociais, econômicas e culturais reforçam visões reducionistas em Educação Ambiental. Além disso, na formação docente percebe-se a ausência de uma visão integrada em questões éticas e epistemológicas na construção do conhecimento em Educação Ambiental. Desse modo, a compreensão do meio ambiente apenas como representação da natureza reflete a dificuldade das disciplinas em interagir de forma integrada com todas as outras áreas do conhecimento, restando ao professor mediar essa importante discussão (MALMANN, 2020, p.50).

Realizar atividades de Educação Ambiental descontextualizadas ou mesmo sem oportunizar a análise e a reflexão teórica, evidencia-se a efetivação de uma ação obsoleta e desnecessária, conforme relatado por Lima (2002, p.9). Ao se esvaziar o significado e a importância da Educação Ambiental, cria-se a oportunidade para as meras reproduções, tão combatidas pela concepção histórico-crítica da educação (MALMANN, 2020, p.50). 
Por essa razão, deve-se criar novas formas de sensibilização e abordagens, uma delas é a questão do uso de filmes em sala de aula, para munir professores com estratégias de ensino não meramente teóricas, mas sim, usá-las como ferramentas audiovisuais que facilitam a percepção do aluno em relação ao mundo exterior (LOREZON et al., 2014, p.4).

A utilização desta ferramenta mostra didaticamente eficaz quando desempenha uma função informativa exclusiva, na qual se almeja transmitir informações que precisam ser ouvidas ou visualizadas e que encontram no audiovisual o melhor meio de veiculação. Pode-se utilizá-lo como reforço da explicação prévia do professor, ou ainda como meio de avaliação eliminando a banda sonora, e atribuindo aos alunos o papel de narradores (ARROIO; GIORDAN, 2006, p.4).

Ressalta-se que a inclusão da temática ambiental nos currículos escolares deve acontecer a partir de atividades diferenciadas, as quais possam conduzir os estudantes a serem agentes ativos no processo de formação de conceitos. Nesse sentido Ferreira e Limberger (2017, p.773) afirmam que a imagem, como um recurso capaz de estimular a curiosidade e múltiplas leituras, pode provocar nos estudantes a necessidade de compreender melhor a relação dos seres humanos e o ambiente e, por conseguinte, despertar comportamentos, posturas e ações comprometidas com o cuidado e a sustentabilidade.

Moran et al. (2001, p.4) relatam que o conhecimento se dá fundamentalmente no processo de interação, de comunicação e a informação é o primeiro passo para conhecer. Neste aspecto, apontam sobre a importância de integrar os meios de comunicação na escola, afirmando que: "[...] os meios de comunicação, principalmente a televisão, desenvolvem formas sofisticadas multidimensionais de comunicação sensorial, emocional e racional, superando linguagens e mensagens que facilitam a interação com o público".

Muito tem sido feito para otimizar a utilização de equipamentos como computadores e televisores em processos de ensino-aprendizagem. No caso do ensino de ciências, o uso dessas tecnologias não é menor (se não for mais significativo) já que a ciência é grande provedora e usuária do conhecimento utilizado pela tecnologia (PAIM, 2006, p.17).

O 'cinema do real' encontra-se predominantemente atrelado a uma ideia geral de produção de imagens mais 'puras', que, nesta condição, atuariam como uma espécie de reflexo fiel da natureza. Não se trata mais de uma natureza selvagem, misteriosa, a que devemos desbravar; não mais a natureza eminentemente exuberante, diversa, "fotogênica"; mas aquela que perde seu vigor, se enfraquece e dá sinais, visíveis e nítidos, de estar em atemorizante perigo. Em outras palavras, "os novos documentários mostram que este planeta está perdendo diversidade e beleza, deixando de ser aquele extraordinário mundo azul para ser uma imagem se decompondo em vários pontos" (TUCHERMAN; CAVALCANTI, 2008, p.41). 
Vieira (2009, p.21) declara que os documentários possuem potencial interpelativo, que pode favorecer 0 interesse do aluno em relação à problemática ambiental apresentada. Ele afirma que o filme documentário, ao apontar e chamar a atenção para aquilo que está "errado", ecologicamente falando, e trazer soluções possíveis para a reversão dos problemas ambientais, pode até mesmo realizar uma reversão deste quadro de devastação que estamos presenciando.

A imagem, como um elemento provocativo da curiosidade, pode proporcionar aos estudantes a interpretação sobre a presença dos seres humanos no ambiente, suas formas de interações e impactos, promovendo alternativas para cuidar do meio ambiente e do desenvolvimento sustentável. Por essa razão, a utilização de vídeos como uma ferramenta didática de sensibilização ambiental pode ser considerada importante atualmente. Isso porque a linguagem utilizada nos vídeos estabelece comunicação significativa com um grande e variado quantitativo de pessoas: seu diálogo está intimamente atrelado ao cotidiano (FERREIRA; LIMBERGER, 2017: p. 767).

\section{Procedimentos Metodológicos}

O presente trabalho está fundamentado em uma abordagem de natureza qualitativa e foi desenvolvido na perspectiva da pesquisa-ação que, de acordo com Thiollent (2005, p.16), pode ser definida como uma metodologia derivada da pesquisa social com base empírica, concebida e realizada em estreita associação com uma ação ou a resolução de um problema coletivo, e na qual pesquisadores e participantes representativos da situação ou problema estão envolvidos de modo cooperativo ou participativo.

Tozzoni-Reis (2010, p. 32) complementa ainda que a pesquisa-ação articula, radicalmente, a produção de conhecimentos com a ação educativa, isto é, por um lado, investiga, produz conhecimentos sobre a realidade a ser estudada e, por outro e simultaneamente, realiza um processo educativo para o enfrentamento dessa mesma realidade. Essa modalidade da pesquisa qualitativa também é conhecida como participante, participativa e pesquisaação-participante ou participativa.

Para concretização deste trabalho foi realizada, inicialmente, pesquisa na literatura científica, especialmente artigos e teses, a partir da base de dados encontrada no Periódicos Capes, Scielo, Bancos de Teses.

A interveção consiste na realização de uma sequência didática (SD), planejada para ser executada em um tempo estimado de $5 \mathrm{~h} / \mathrm{a}$ e foi realizada envolvendo 50 estudantes de uma Escola de Referência em Ensino Médio localizada no município de Moreno-PE. A sequência didática foi dividida em quatro momentos cujos objetivos estão descritos no quadro a seguir: 
Quadro 1: Descrição das atividades desenvolvidas na sequência didática.

\begin{tabular}{|c|c|c|c|}
\hline \multicolumn{2}{|c|}{ Sequência Didática - Um lugar chamado “Fora”: discutindo sobre o descarte incorreto do lixo } \\
e a problemática dos plásticos na atualidade.
\end{tabular}

Fonte: Autora, 2020.

O detalhamento dos momentos desenvolvidos na sequência didática está descrito abaixo:

\section{Primeiro momento $(2 \mathrm{~h} / \mathrm{a})$ - exibição do documentário "oceanos de plástico3".}

O primeiro momento da sequência didática consiste na exibição do documentário "Oceanos de Plástico". O documentário tem duração de 100min e aborda de forma didática as consequências do descarte incorreto de resíduos e a problemática dos plásticos na sociedade atual.

\section{Segundo momento (1h/a): debate sobre a relação dos seres humanos com a natureza.}

Nessa etapa, foi realizada uma roda de conversa para debater sobre a relação antrópica com a natureza a partir da perspectiva do documentário. Os estudantes foram questionados sobre:

- O atual modo de consumo da sociedade moderna;

- O uso indiscriminado de plásticos e seu descarte;

- As consequências do descarte incorreto de resíduos;

- O alcance da ação antrópica na natureza e suas consequências;

- As possibilidades de reutilização das embalagens plásticas antes do descarte;

${ }^{3}$ Título: Oceanos de plástico. Autor: Craig Leeson. Duração: 1h40min 


\section{Terceiro momento (1h/a): confecção produção de cartazes}

Neste momento, os estudantes foram divididos em grupos de 5-6 participantes para confecção de cartazes que abordassem através de desenhos os três tópicos a seguir: 1. Pontos vistos no documentário; 2 . A problemática dos plásticos na sociedade atual; 3. Possíveis soluções para os questionamentos discutidos na aula anterior.

\section{Quarto momento (1h/a): socialização e discussão}

Neste momento, os estudantes socializaram com a turma os cartazes que confeccionaram em grupo e foi proporcionado um momento de discussão acerca das soluções sugeridas para os questionamentos levantados no Momento 2.

\section{Resultados e Discussão}

Durante a exibição do documentário, os estudantes mostraram total atenção e manifestavam expressões de espanto, em especial, quando eram exibidas cenas que mostravam a quantidade de plásticos nos mares e, principalmente, quando mostrava animais agonizando em decorrência da ingestão de plástico. A partir dessas observações, foi possível perceber que o documentário proporcionou surpresa e espanto na maioria dos estudantes

Nesse sentido, em consonância com Ferreira e Limberger (2017, p.773), a motivação promovida pelo vídeo pode auxiliar na problematização das questões ambientais gerando discussões necessárias à completa compreensão dos problemas relacionados, que dificilmente podem ser contemplados apenas pelo livro didático.

A linguagem utilizada nos vídeos estabelece comunicação significativa com um grande e variado quantitativo de pessoas: seu diálogo está intimamente atrelado ao cotidiano (FERREIRA; LIMBERGER, 2017, p.772). Assim, de acordo com Paim (2006), o enfoque abordado por vídeos educativos pode proporcionar a constituição de um aprendizado através da interação dos estudantes ao reconhecerem neste, situações do seu cotidiano ou de sua relevância.

Moran et al. (2001, p. 36) defendem o uso do vídeo na educação escolar e, portanto, na Educação Ambiental, justificando que, para o aluno, vídeo significa 'descanso' e não 'aula' o que por si só pode modificar as expectativas em relação ao seu uso. Assim, essa expectativa positiva pode ser aproveitada para atrair o aluno para os assuntos do planejamento pedagógico escolar e ainda para introduzir um novo assunto, despertando a curiosidade e a motivação para novos temas.

Após a exibição do documentário, os estudantes foram reunidos para realização de uma roda de conversa com a finalidade de debater acerca dos problemas ambientais levantados no documentário. Os estudantes eram instigados com questionamentos que os levavam a refletir sobre as 
consequências da ação antrópica no meio e na qualidade de vida de inúmeros organismos. Essa etapa permitiu avaliar a percepção dos estudantes acerca do documentário associada ao atual contexto ambiental e quais as consequências de nossas ações na natureza.

Nesse momento, foi possível perceber que muitos estudantes não tinham noção de como ações antrópicas aparentemente pontuais/locais podem refletir na vida de organismos que vivem a quilômetros de distância - Esse ponto foi abordado durante o documentário, na cena em que mostra como vivem os albatrozes da llha de Midway situada no Oceano Pacífico - nessa ilha, pesquisadores encontram resíduos de diversas partes do mundo, que através das correntes marítimas são levados para lá. Diante da imensidão de lixo, os albatrozes acabam se alimentando dos resíduos que encontram e acabam morrendo por inanição ou asfixia.

Malmann (2020, p.46) enfatiza que a percepção de que a humanidade deve ser analisada a partir da integração entre desenvolvimento e meio ambiente é resultante da crença nas virtudes do progresso e a atenção às diferentes escalas de tempo, uma vez que para a natureza, a recuperação pode levar décadas, séculos ou até mesmo milênios e, também, devido à preocupação com as consequências das ações locais que podem interferir em todo o planeta ou mesmo em regiões distantes dali.

Além disso, foi possível discutir sobre o atual modo de consumo da sociedade moderna bem como sobre as consequências do descarte incorreto de resíduos. Os estudantes foram levados a refletir sobre como os seres humanos afetam de forma tão significativa a natureza causando problemas que repercutem a nível global.

Vale enfatizar que, um ponto destacado pelos estudantes, foram os aspectos envolvendo a quantidade crescente de plástico que toma conta dos oceanos e a forma como isso interfere diretamente na vida humana, não somente pela poluição em si, mas pelas micropartículas liberadas pelo plástico que se acumulam nos organismos ao longo da cadeia alimentar e chega até nós por meios da ingestão de frutos do mar. Nesse sentido, um estudante fez 0 seguinte comentário: "Professora, estamos nos alimentando de plásticos".

Então, nesse instante, a professora os levou a refletir que a forma como lidamos com a natureza produz impactos que afetam diretamente a natureza, mas que, consequentemente, os transtornos disso são sentidos por nós mesmos. Nessa direção, Jacobi (2003, p.195) reforça a necessidade de estimular uma participação mais ativa da sociedade no debate dos seus destinos, como uma forma de estabelecer um conjunto socialmente identificado de problemas, objetivos e soluções.

Após isso, no momento da confecção dos cartazes (Figura 1), a professora acompanhava de perto as discussões grupo a grupo e observava as dificuldades encontradas, os pontos de convergência e divergência. Os estudantes eram avaliados a partir da discussão em seu grupo de trabalho a 
partir da sua opinião e participação na montagem do cartaz. Alguns estudantes desenharam na seção 3 (possíveis soluções para os problemas ambientais levantados) pessoas recolhendo lixo das ruas e praias. Nessa situação, a professora instigava a reflexão dos estudantes sobre a possibilidade de soluções que pudessem anteceder o descarte incorreto dos resíduos.

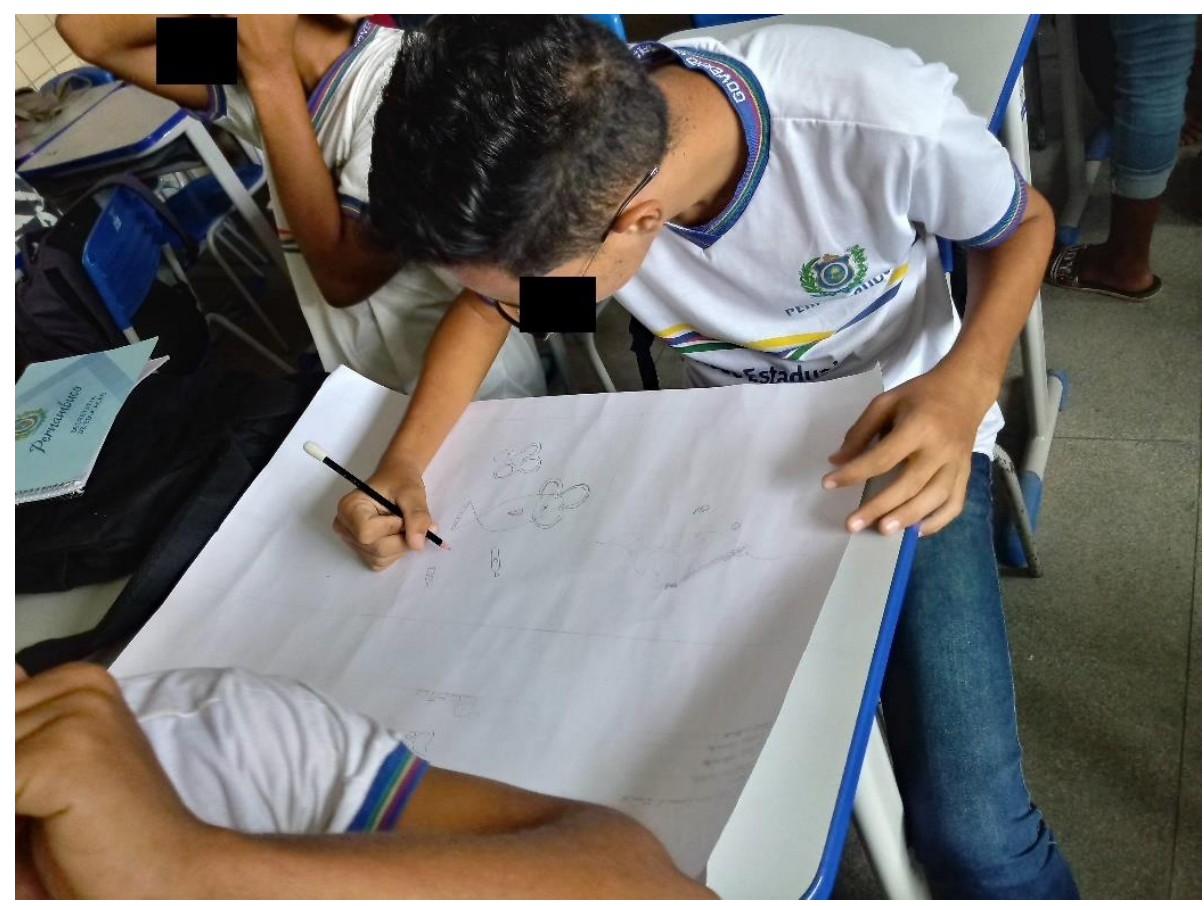

Figura 1: Confecção de cartazes pelos estudantes. Fonte: Autora, 2020

Um dos estudantes desenhou uma pessoa segurando um livro e fez a seguinte afirmação: "Professora, a única solução para tudo isso é a educação." A professora de imediato elogiou a reflexão do aluno e o estimulou a refletir sobre as formas de disseminar/multiplicar conhecimento.

De acordo com Vido et al. (2016, p. 45), é imprescindível repensarmos, hoje, a relação sociedade-natureza para enfrentar a crise ecológica que vivemos. Ela encontra-se permeada de valores, que orientam nossas ações até mesmo inconscientemente. Sendo assim, torna-se necessário revisar e construir novos valores, novas concepções acerca dos seres humanos, da natureza e do mundo.

Nesse sentido, Ferreira e Limberger (2017, p.771) afirmam que no ensino médio, o pensamento crítico, contextualizado e político, e a cidadania ambiental devem ser ainda mais aprofundados, podendo ser incentivada a atuação de grupos não apenas para a melhoria da qualidade de vida, mas especialmente para a busca de justiça socioambiental.

No momento da socialização dos cartazes confeccionados, foi feito um grande círculo para que os estudantes pudessem compartilhar com todos suas 
percepções. Foi um momento em que foi possível discutir sobre nosso papel como cidadãos e sobre como podemos buscar soluções para minimizar nossos impactos na natureza.

\section{Considerações Finais}

O desenvolvimento da Sequência Didática revela que é possível sensibilizar os estudantes por meio de atividades que demandam baixo custo e estruturadas a partir de recursos disponíveis na maioria dos espaços escolares. O conjunto de recursos e estratégias adotadas impactaram de forma direta no engajamento dos estudantes e mobilizaram discussões fundamentais para 0 momento em que vivemos.

A utilização de vídeos/documentários é uma ferramenta que os estudantes se mostram muito receptivos tendo em vista que difere das aulas tradicionais e por essa razão, eles se sentem mais motivados e o engajamento se torna mais efetivo.

Dessa forma, conclui-se que a inserção da Educação Ambiental no Ensino Médio é possível de ser realizada promovendo engajamento discente na reflexão acerca da ação antrópica no meio, estimulando mudanças de atitudes e transformação de valores, bem como reforçando no estudante sua capacidade crítica na busca por solução de problemas.

\section{Agradecimentos}

À Coordenação de Aperfeiçoamento de Pessoal de Nível Superior CAPES e ao Mestrado Profissional em Ensino de Biologia da Universidade Federal de Pernambuco - Centro Acadêmico de Vitória.

\section{Referências}

ALMEIDA, N.C.C. et al. Educação Ambiental: a conscientização sobre o destino de resíduos sólidos, o desperdício de água e o de alimentos no município de Cametá/PA. Rev. bras. Estud. pedagogia., Brasília, v. 100, n. 255, 2019.

ARROIO, A.; GIORDAN, M. O vídeo educativo: Aspectos da organização do ensino. Química Nova na Escola, n.24, 2006.

DIDONET, D.L.M.; SOUZA, J.P.; SOUZA, T.A. Práticas da Educação Ambiental: uma proposta de educação para o desenvolvimento sustentável. Rev. Eletrônica do Curso de Pedagogia do Campus, Jataí: UFG, v.11, n.1, 2015.

FERREIRA, E.G.S.; LIMBERGER, D.C.H. Vídeo-documentário como ferramenta sensibilizadora de Educação Ambiental, nos Butiazais de Tapes (RS). Rev. Elet. Cient. UERGS, v. 3, n. 4, 2017. 
JACOBI, P. Educação Ambiental, cidadania e sustentabilidade. Cadernos de Pesquisa, n. 118, 2003.

KONDRAT, H.; MACIEL, M. D. Educação Ambiental para a escola básica: contribuições para o desenvolvimento da cidadania e da sustentabilidade. Revista Brasileira de Educação, v.18, n.55, 2013.

LEFF, E. Epistemologia ambiental. São Paulo: Cortez, 2001.

LIMA, G.F.C. Educação e sustentabilidade: possibilidade e falácias de um discurso. Anais do Encontro Associação Nacional de Pós Graduação e Pesquisa em Ambiente e Sociedade, 1, 2002, Indaiatuba.

LOREZON, D.; SCHEID, N.M.J.; SOARES, B.M. Os filmes e os estudos de Educação Ambiental. Ponta Grossa: Anais do IV Simpósio Nacional de Ensino de Ciência e Tecnologia, 2014.

MALMANN, A.; CARNIATTO, I.; PLEIN, C. A Educação Ambiental do ponto de vista das concepções de desenvolvimento sustentável na escola do campo. São Paulo: RevBEA, v.15, n.1, 2020.

MEDEIROS, A.B. et al. Importância da Educação Ambiental na escola nas séries iniciais. Revista Faculdade Montes Belos, v. 4, n. 1, 2011.

MORAN, J.M.; MASETTO, M.T.; BEHRENS, M.A. Novas tecnologias e mediação pedagógica. $3^{\circ}$ ed. Campinas: Papirus, 2001.

OLIVEIRA, J.T.; MACHADO, R.C.D.; OLIVEIRA, E.M. Educação Ambiental na escola: um caminho para aprimorar a percepção dos alunos quanto à importância dos recursos hídricos. Periódico Eletrônico Fórum Ambiental da Alta Paulista, São Paulo, v. 11, n. 4, 2015.

PAIM, P.G. 2006. 129f. A história da borracha na Amazônia e a Química Orgânica: Produção de um vídeo didático-educativo para o Ensino Médio. Dissertação (Mestrado Profissionalizante em Ensino de Ciências) - Mestrado em Ensino de Ciências, Instituto de Química, Universidade de Brasília. Disponível em: < https://repositorio.unb.br/handle/10482/9036> . Acesso em: 12 de junho de 2020.

PEREIRA, V. A.; GIBBON, C. A. A Educação Ambiental no ensino: Investigando as abordagens, percepções e desafios na realidade de uma escola pública em Rio Grande (RS). RevBEA, São Paulo, v9, n. 2, p.376-394, 2014.

RAMBO, L.; RENK, A.A. A relação homem/natureza-animais: uma revisão da literatura sobre o descaminho da cultura ocidental. Canoas: Revista de Ciências Ambientais, v.2, n.2, 2008. ISSN 1981-8858.

SANTOS, B.S. Para um novo senso comum: a ciência, o direito e a política na transição paradigmática. São Paulo: Cortez, 2004.

THIOLLENT, M. Metodologia da pesquisa-ação. 14. ed. São Paulo: Cortez, 2005. 
TOZZONI-REIS, M. F. C. A pesquisa e a produção de conhecimentos: introdução à pesquisa em educação. Curso de pedagogia da Unesp. 2010. Disponível em: https://acervodigital.unesp.br/bitstream/123456789/195/3/01d10a03.pdf> Acesso em: 22 de abril de 2020.

TREIN, E. A contribuição do pensamento marxista à Educação Ambiental. In: LOUREIRO, C. F. B. (Org.). A questão ambiental no pensamento crítico: natureza, trabalho e educação. Rio de Janeiro: Quartet, 2007.

TUCHERMAN, I.; CAVALCANTI, C.C.B. Um novo gênero cinematográfico: o documentário catástrofe. Revista FAMECOS, Porto Alegre, n. 35, n. 1, 2008.

VIDO, N.R.; DEGASPERI, T.C.; NARDY, M. Energia que gera ou destrói a vida? In: BONOTTO, D.M.B.; CARVALHO, M.B.S.S. (Org.). Educação Ambiental e valores na escola buscando espaços, investindo em novos tempos. São Paulo: Cultura Acadêmica, 1.ed., 2016. ISBN 978-85-7983-762-3.

VIEGAS, L. L.; OLIVEIRA, J. B. de; SILVA, D. S. A alma de nossas árvores: um diálogo entre o conceito aristotélico de alma, a Educação Ambiental, o ensino de Filosofia e a prática artística. São Paulo: Cultura Acadêmica, 1.ed., 2016. ISBN 978-85-7983-762-3.

VIEIRA, F. Z. A utilização didática do cinema para a aprendizagem da Educação Ambiental. Dissertação (Mestrado). Universidade Estadual de Ponta Grossa. Ponta Grossa, 2009. 